OECD Regional Development Working Papers 2014/08

\title{
Metropolitan Governance of Transport and Land Use in Chicago
}




\section{OECD REGIONAL DEVELOPMENT WORKING PAPERS}

This series is designed to make available to a wider readership selected studies on regional development issues prepared for use within the OECD. Authorship is usually collective, but principal authors are named. The papers are generally available only in their original language English or French with a summary in the other if available.

OECD Working Papers should not be reported as representing the official views of the OECD or of its member countries. The opinions expressed and arguments employed are those of the author(s).

Working Papers describe preliminary results or research in progress by the author(s) and are published to stimulate discussion on a broad range of issues on which the OECD works. Comments on Working Papers are welcomed, and may be sent to either gov.contact@oecd.org or the Public Governance and Territorial Development Directorate, OECD, 2 rue André-Pascal, 75775 Paris Cedex 16, France.

Authorised for publication by Rolf Alter, Director, Public Governance and Territorial Development Directorate, OECD.

OECD Regional Development Working Papers are published on http://www.oecd.org/gov/regional/workingpapers

Applications for permission to reproduce or translate all or part of this material should be made to: OECD Publishing, rights@oecd.org or by fax 33145249930.

(C) OECD 2014 


\title{
METROPOLITAN GOVERNANCE OF TRANSPORT AND LAND USE IN CHICAGO
}

\author{
Olaf Merk $^{1}$
}

\begin{abstract}
This study aims to assess the degree of institutional fragmentation of transport and land use planning in Chicago and to assess the main challenges related to this institutional fragmentation. It provides an overview of local governments in metropolitan Chicago and mechanisms for metropolitan coordination, including organisations at the metropolitan scale, dealing with planning, land use and transport. Five main challenges related to institutional fragmentation in transport and land use planning are identified: a lack of (1) interconnectivity, (2) coherence across transit modes, (3) regional freight planning, (4) accountability and (5) implementation power of regional planning and transport objectives. These challenges are analysed. The concluding section suggests some avenues for reform that could be explored in order to overcome the challenges of metropolitan fragmentation in transport and land use in Chicago.
\end{abstract}

Keywords: Urban transport, public transit, metropolitan governance, urban infrastructure, Chicago.

JEL Classification: R4, R5.

1. The report has been written by Olaf Merk, as part of a project on Urban Trends and Governance, directed by Rüdiger Ahrend. The report has benefitted from discussions with relevant local actors and stakeholders in January 2014 in Chicago. Valuable comments during the drafting of the report were provided by William Tompson, Rüdiger Ahrend and Soo-Jin Kim from the OECD, as well as Peter Creticos (President/Executive Director, Institute for Work \& the Economy) and Stephen Schlickman (Executive Director - Urban Transportation Center, University of Illinois Chicago). Please address further enquiries about this work to Olaf Merk (olaf.merk@oecd.org) 
TABLE OF CONTENTS

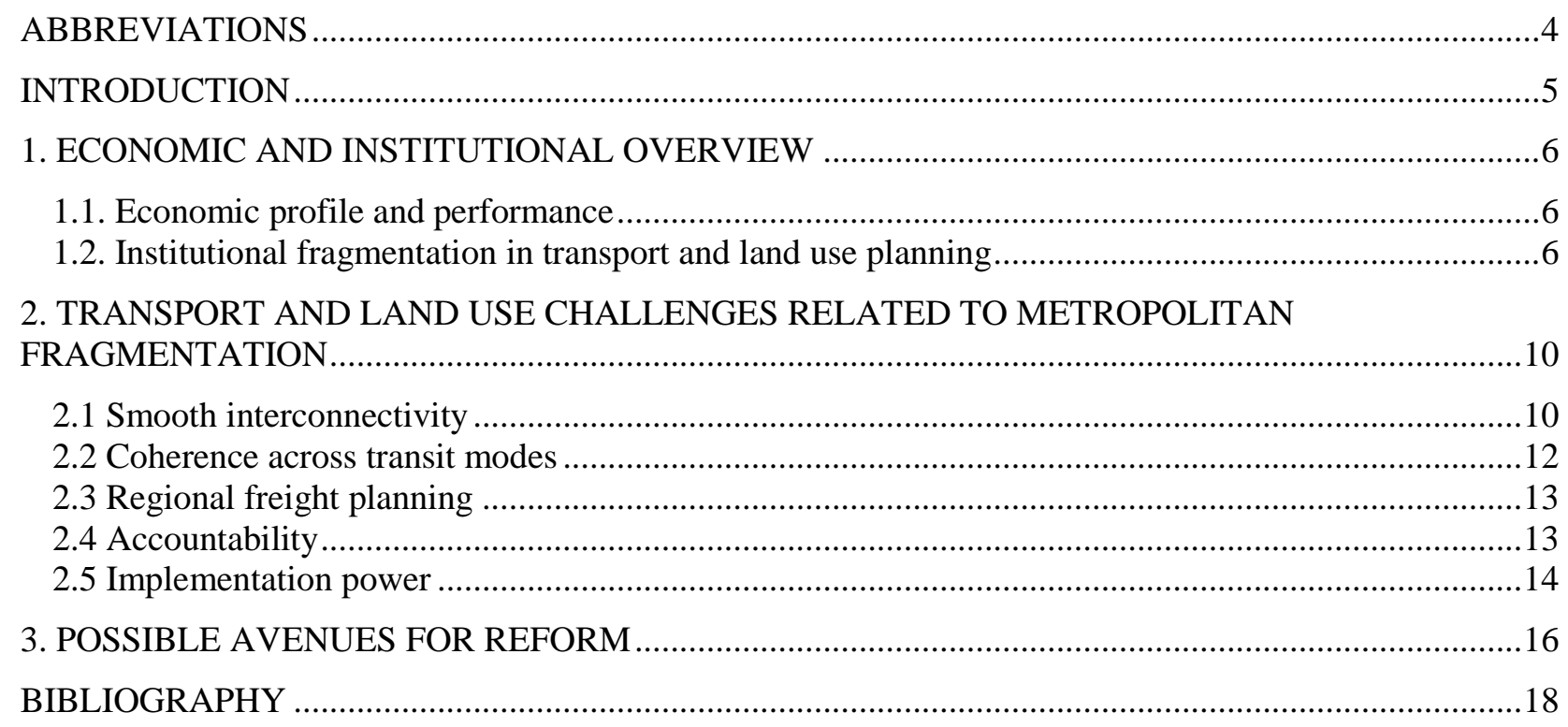




\section{ABBREVIATIONS}

CATS - $\quad$ Chicago Area Transportation Study

CDA - $\quad$ City of Chicago Department of Aviation

CMAP - $\quad$ Chicago Metropolitan Agency for Planning

COG - $\quad-\quad$ Councils of Government

CREATE - Chicago Region Environmental and Transportation Efficiency programme

CTA $\quad-\quad$ Chicago Transit Authority

HUD - - US Department of Housing and Urban Development

IIPD $\quad-\quad$ Illinois International Port District

MPC - $\quad$ Metropolitan Planning Council

MPO - $\quad$ Metropolitan planning organisation

NIPC $\quad-\quad$ Northeastern Illinois Planning Commission

NIRPC - $\quad$ Northwestern Indiana Regional Planning Commission

PPP $\quad$ - $\quad$ Public-Private Partnership

RTA $\quad-\quad$ Regional Transportation Authority

SEWRPC - Southeastern Wisconsin Regional Planning Commission

WBC $\quad-\quad$ World Business Council 


\section{INTRODUCTION}

Metropolitan fragmentation is a barrier to the realisation of urban agglomeration effects. These agglomeration effects can be considered the main advantage of cities: they provide deeper labour markets, more extensive markets for services and the knowledge spillovers generally associated with innovation. Metropolitan fragmentation can hinder the smooth movement of people and goods over the metropolitan areas and thus hinders growth. For a given population size, a metropolitan area with twice the number of municipalities is associated with around six per cent lower productivity, an effect that is mitigated by almost half by the existence of a governance body at the metropolitan level (Ahrend et al. 2014). This case study of Chicago forms part of an OECD project on Urban Trends and Governance, together with five other case studies that focus on metropolitan transport and land use governance. This case study aims to assess the degree of metropolitan fragmentation and its impact on transport and land use planning in Chicago, and to identify possible avenues for reform.

Chicago has a long and established tradition of urban and regional planning, which makes it an interesting test case for urban areas across the world. The famous 1909 Plan of Chicago of Daniel Burnham has become one of the benchmarks of American urban planning, subject to widespread praise, but also to fervent criticism, for example in the American urban planning classic The Death and Life of Great American Cities (Jacobs, 1961). But even before the Burnham plan, urban planning of some sorts already took place in Chicago (Smith, 2006). Following the 1909 Plan of Chicago, various new plans for Chicago have been developed over the last century, becoming increasingly regional in scope, reflecting the ongoing spread of the metropolitan area over a wider geographical area (Schwieterman and Mammoser, 2009). The most recent plan for Chicago is GO TO 2040, developed by the Chicago Metropolitan Agency for Planning (CMAP).

This case study on Chicago follows up on previous OECD work on Chicago. The OECD Territorial Review of the Chicago Tri-State Metropolitan Area, released in 2012, provided an assessment of the Chicago area with respect to the economy, policies and governance; one of the chapters in this report focused on transport and logistics in the Chicago region. The current case study builds on this chapter and expands on the assessment of transport and land use governance mechanisms. As highlighted in the 2012 Review, Chicago is one of North America's main logistics hubs, which makes the performance of transport infrastructure crucially important to the region. The Review adopted a definition of the Chicago region that goes beyond the boundaries of the State of Illinois and covers parts of the States of Indiana and Wisconsin: the Chicago Tri-State Metropolitan Area. The current case study adopts multiple definitions of Chicago. In addition to the wider Tri-State Metropolitan Area, it also focuses on what is in the current local policy debate most widely considered to be the metropolitan area, consisting of six counties in Northeastern Illinois, which we will refer to here as the metropolitan area of Chicago. ${ }^{2}$

The following sections aim to identify the institutional fragmentation of transport and land use planning in Chicago and to assess the main challenges related to this institutional fragmentation. The concluding section suggests some avenues for reform that could be explored in order to solve the challenges of metropolitan fragmentation in transport and land use in Chicago.

2. The Chicago Metropolitan Statistical Area as defined by the US Census contains 14 counties and approximately 10 million inhabitants; the OECD metropolitan database applies a different definition: a more constrained area of around 9.4 million inhabitants. 


\section{ECONOMIC AND INSTITUTIONAL OVERVIEW}

\subsection{Economic profile and performance}

Chicago is an economic powerhouse with a variety of strong assets. Its economy represented approximately USD 500 billion in 2010, which makes it the third largest metropolitan economy in the US. Chicago has a very diversified regional economy, with strong presence in financial services, wholesale trade and retail, health, and transport and logistics. In addition, it has a relatively strong specialisation in manufacturing, a well-educated population and high rates of entrepreneurship. Chicago is home to many corporate headquarters, which is facilitated by excellent global connectivity (via air), good quality of life and a whole range of urban amenities, including prominent universities, research institutes and cultural institutions.

The Chicago metropolitan region faces various economic challenges. Its annual GDP growth rate has been just about half the US average $(0.8 \%$ vs. $1.6 \%)$ during the past decade. Its regional GDP per capita has also grown more slowly than that of other major U.S. metropolitan areas, such as New York and Los Angeles. Between 2000 and 2010, the rate of employment in the Chicago region declined at an average annual rate of $0.7 \%$, as compared to a decline of $0.15 \%$ in the national average. In addition, the Chicago region has experienced slow annual growth in population $(0.4 \%$ over the last decade, whereas population growth in the country as a whole was $0.9 \%$ ) and productivity improvement has slowed in recent years (WBC, 2012).

\subsection{Institutional fragmentation in transport and land use planning}

\section{A panoply of local governments in metropolitan Chicago}

Chicago is generally considered to be one of the most institutionally fragmented metropolitan areas in the United States - and indeed worldwide. This fragmentation has been explained by two factors. First, Illinois laws limit municipal indebtedness and revenues, encouraging the creation of special purpose districts with their own bonding power and taxing authority. The second explanation is the historic citysuburban hostility dating back to the late nineteenth century. Political divergences, with urban Democratic and suburban Republican competition for the control of the Illinois General Assembly, intensified this fragmentation in the 1980s and 1990s (Lindstrom 2010). The City of Chicago is a municipality included in Cook County, which spans a wider area and also includes suburban municipalities. ${ }^{3}$ The metropolitan area of Chicago consists of the city of Chicago and approximately 270 other municipalities, $80 \%$ of which have less than 25,000 inhabitants. These sub-urban municipalities form part of six counties that comprise the metropolitan area.

Institutional fragmentation in Chicago mirrors the fragmentation and multiplicity of government actors in the state of Illinois, in which Chicago is located. According to the Illinois Office of the Comptroller, the State of Illinois in 2011 encompassed 8400 units of local government, which is a large number of local government units in international perspective. There are five basic types of local government in Illinois, all creatures of the state government. Illinois has 102 counties, around 1300 municipalities, 1400 townships, 900 school districts and 3000 special districts.

Various sub-national governments have responsibilities related to transport and land use planning. Counties are responsible for construction and maintenance of secondary roads and bridges, municipalities

3. A small piece of Chicago (the uninhabited land at O'Hare Airport) is in DuPage County. 
for local streets, traffic control and adoption of local laws, called "ordinances" regulating local matters, including zoning. Townships only exist in those counties where a county-wide referendum has created them. One of their main functions is the construction and maintenance of roads and bridges in unincorporated areas. Townships in Illinois also have zoning authority, but only where the county has not adopted a zoning ordinance. Transport-related special districts include airport authorities, mass transit districts, port districts, road and bridge districts, road districts and transport authorities. The number of transport-related special districts is relatively small compared to other functions (park, recreation, library and fire protection): in the Chicago Tri-State Metro-Region there are in total 784 special districts, five of which in air transport, nine in mass transit, seven in highways and three in water transport (OECD, 2012). In addition to the local governments, the State of Illinois has important powers within the domain of road transport. The Illinois Department of Transportation is responsible for maintenance of state public roadways, funding rail, public transit and airport projects; and administering fuel tax and federal funding to local jurisdictions in the state. The Illinois State Toll Highway Authority is responsible for provision of toll-supported highways.

Figure 1.1. Map of Chicago Metropolitan Statistics Area

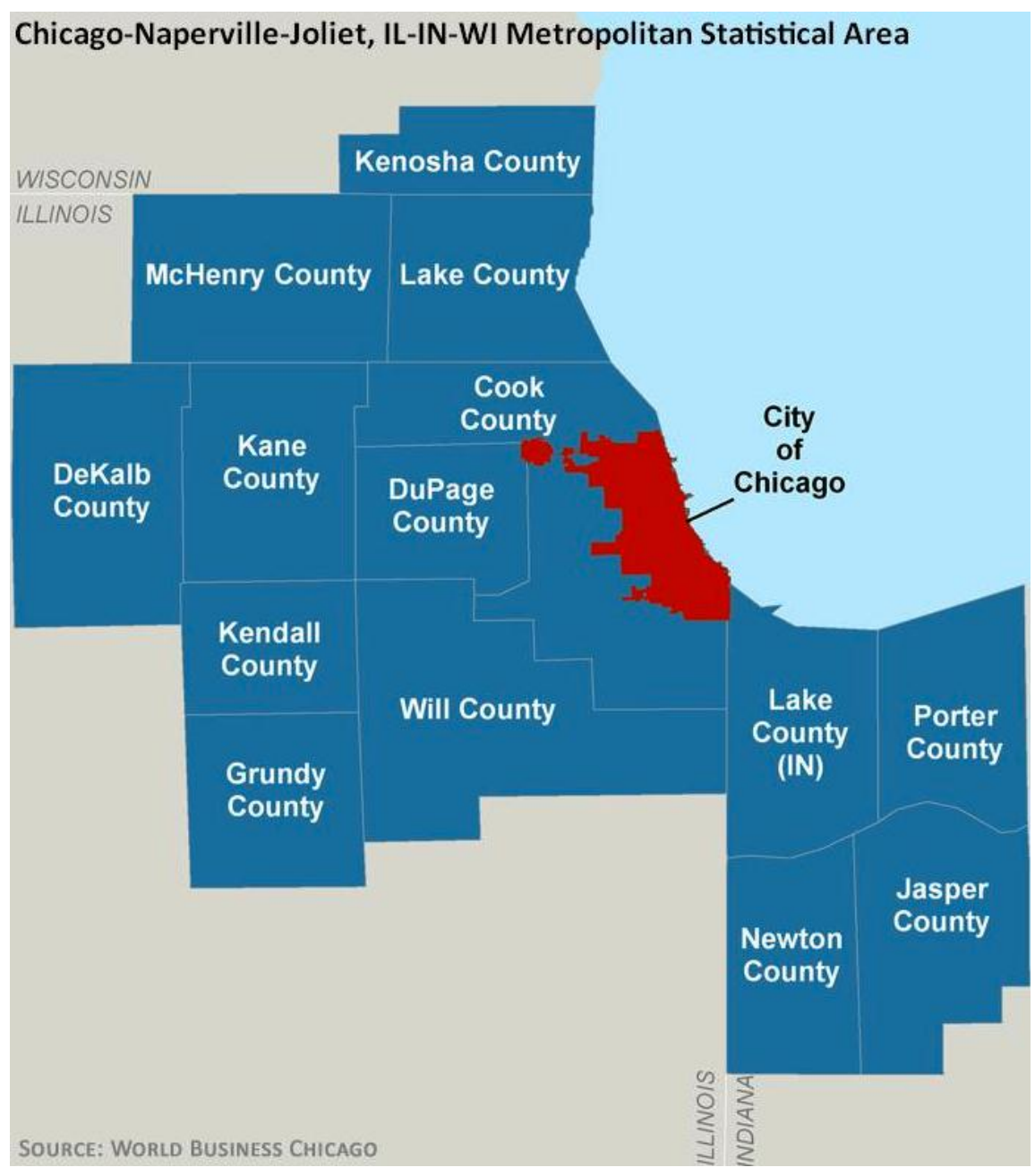

An important mechanism for overcoming the institutional fragmentation in Chicago consists of cooperation between municipalities. This takes the form of agreements to provide services in the region. For example, in Cook County, joint action agencies and special districts were established by local governments. Mayors in suburbs in the Chicago metropolitan area have since the 1950s cooperated in 
suburban Councils of Government (COGs), voluntary associations to meet the challenges they faced. These informal meetings set the pattern for nine COGs to join the city of Chicago in 1997 to work together in the Metropolitan Mayors Caucus to resolve common challenges. At the beginning, only issues were addressed for which there was a consensus (such as the power outages of the electricity provider Commonwealth Edison and a Clean Air Campaign), but the Mayors Caucus was later also involved in more controversial debates (Lindstrom, 2010). The Metropolitan Mayors Caucus was incorporated in 2001, with task forces on issues such as freight rail, ground transport and regional growth, as well as on various non-transport related topics including emergency preparedness, service delivery and diversity issues. The Mayors Caucus has had a long-standing involvement in regional transport issues. It strongly supported the use of federal funding for transit, highway and safety programmes for the region. The approval of the Mayors Caucus was critical for the creation of the Chicago Metropolitan Agency for Planning (CMAP), and the restructuring of the Regional Transport Authority in 2008, both organisations that will be discussed below. In addition they recommended funding support for the Chicago Region Environmental and Transportation Efficiency Project (CREATE), a public-private partnership to resolve the freight rail gridlock in the region (Lindstrom, 2010).

Cooperation at the metropolitan level has also been stimulated by business and civil society associations, including the Commercial Club of Chicago, the Metropolitan Planning Council (MPC), the World Business Council (WBC) and the Chicagoland Chamber of Commerce. For example, the Commercial Club of Chicago, uniting business leaders in the Chicago region, issued a report in 1999, entitled Chicago Metropolis 2020 calling for the region to unite to solve its problems including on transport. The committee established Chicago 2020 to pursue this agenda. The MPC informs policymaking and influences policy agendas with well-informed reports and documentation.

\section{Government organisations at the metropolitan scale}

Additional ways to combat institutional fragmentation in Chicago consist of cooperation in regional organisations. Within the area of transport and land use planning, two main organisations exist: the Chicago Metropolitan Agency for Planning (CMAP) and the Regional Transportation Authority (RTA), which will be described and analysed below.

\section{Chicago Metropolitan Agency for Planning}

The Chicago Metropolitan Agency for Planning (CMAP) was created in 2006 based on the 2005 Regional Planning Act, to address development and transport challenges in seven counties in north-eastern Illinois: Cook, DuPage, Kane, Kendall, Lake, McHenry and Will. Its aim is to plan for public and private investments in the area and integrate plans for land use and transport. The CMAP merged the operations of the Chicago Area Transportation Study (CATS) and the Northeastern Illinois Planning Commission (NIPC); CATS was responsible for regional transport planning as the federally designated Metropolitan Planning Organisation (MPO) for the Chicago region; and NIPC for regional land use planning. Though NIPC had no authority to implement its land use plans, CATS had in theory the ability to impose its transport planning on the region but in practice could not.

CMAP is responsible for developing at least every five years a comprehensive regional plan that integrates land use and transport. This plan presents the goals, policies, guidelines and recommendations to guide the physical development of the region. Elements that are included in this plan are official forecasts, inter-sectoral land use and transport policies, a plan for a coordinated and integrated transport system consisting of a multimodal network of facilities and services to be developed over a 20 -year period. Based on this plan a listing of proposed public investment priorities in transport and other facilities and utilities is made. In addition, the comprehensive regional plan can contain proposals for model ordinances and agreements that may be enacted by local governments, as well as recommendations for legislation that may 
be necessary to implement the plan. CMAP's official forecasts and plans are the foundation for all planning in the region, whilst units of local governments continue to maintain control over land use and zoning decisions. The Board of CMAP may review and comment on proposed county and municipal plans. $^{4}$

CMAP published its comprehensive regional plan in 2010, called GO TO 2040, after three years of research and extensive public outreach. In addition to transport and land use, the plan also focuses on taxation, housing, water efficiency, health, local food and energy efficiency. The plan was adopted unanimously by the leaders of the seven counties covered by CMAP. Currently, CMAP focuses on supporting the implementation of GO TO 2040. This has been facilitated by a grant from the US Department of Housing and Urban Development (HUD) to CMAP for technical assistance to communities seeking to implement GO TO 2040. As part of the assistance to local governments, the CMAP has also provided handbooks, such as the Handbook of Planning Law Principles and Practices for Northeastern Illinois.

\section{Regional Transportation Authority}

The Regional Transportation Authority (RTA) in Chicago has the responsibility to develop, implement and enforce plans for adequate, efficient and coordinated public transport, provide financial review of the providers of public transport in the region and facilitate public transport provided by the three Service Boards. These Service Boards refer to the three transit agencies in Northeastern Illinois: the Chicago Transit Authority (CTA), Metra and Pace. CTA operates mass transit (buses and trains) in Chicago and adjacent suburbs, Metra commuter rail and Pace the suburban bus system, overlapping with the CTA system in the Cook County suburbs. The RTA is the oversight body for these operators; the RTA has its own taxing powers, currently exerted through $1.25 \%$ or $0.5 \%$ (depending on the jurisdiction where a purchase is made) of the sales tax. The RTA has the legislative requirement, as part of the 2008 RTA Act, to update the regional transit strategic plan every 5 years. In 2013 the RTA adopted the Regional Transit Strategic Plan, updating the 2007 Moving Beyond Congestion Strategic Plan. The plan is intended to serve as a roadmap for regional transit and is a collaborative effort of the RTA, its Service Boards and its stakeholders.

The RTA reflects the strong city-suburb divergence in the Chicago metropolitan area: when the RTA was established through a referendum in the 1970s the overwhelming majority of the positive votes were cast in the city of Chicago (Young et al., 2007). The CTA is a Chicago-dominated agency (with four of the seven board members appointed by Chicago and three by the State of Illinois), whereas Metra and Pace are predominantly suburban governed agencies, running the suburban commuter rail and buses respectively. Subsequent restructuring of the RTA (e.g. in 1983) has not changed this dynamic; rather than proposing a unified regional transport system, the enabling legislation in 1983 continued the fragmentation and patchwork service (Lindstrom, 2010). According to some observers the impotence to overcome the citysuburban divide can be explained by the relative absence of the state of Illinois in regional public transport and land use planning (Lascano and Durango-Cohen, 2012).

4. The Board of CMAP consists of 15 voting members: five appointed by the mayor of Chicago, five members representing the non-urban part of Cook County, and the other five representing the other counties, appointed by their local government (most of the cases jointly municipal/county appointment). 
Table 1.1. Overview of main government actors in metropolitan transport and planning in Chicago

\begin{tabular}{|l|l|}
\hline Name & Function \\
\hline State of Illinois (Transportation Dept., Toll way) & Construction, maintenance of roads and toll roads \\
\hline Chicago Metropolitan Agency for Planning & Strategic regional planning for metropolitan Chicago \\
\hline Regional Transportation Authority (RTA) & Regional transit planning and budget oversight over the three operators \\
\hline Chicago Transit Authority & Transit operator for Chicago and adjacent suburbs(rail and buses) \\
\hline Metra & Suburban commuter rail operator \\
\hline Pace & Suburban bus operator \\
\hline Counties & Construction, maintenance secondary roads and bridges \\
\hline Municipalities & Local streets, traffic control, local planning and zoning \\
\hline
\end{tabular}

\section{TRANSPORT AND LAND USE CHALLENGES RELATED TO METROPOLITAN FRAGMENTATION}

Various mechanisms have helped to mitigate institutional fragmentation in Chicago, such as CMAP, RTA, the Mayors Caucus and the civic society involvement at the regional scale, as described above. The various administrative jurisdictions of these organisations and agencies are (more or less) aligned along the lines of the six counties covering the metropolitan area of Chicago. ${ }^{5}$ In addition, various policy goals are aligned: the RTA plan is aligned with GO TO 2040 plan of CMAP, including on the emphasis on liveable communities, achieving a state of good repair for the region's transit assets, modernising the transit system, as well as the interest in innovative financing approaches. On the larger regional scale, the three MPOs in the three states covering the Tri-State Chicago region (CMAP, NIRPC, SEWRPC) have sought to increase cooperation and coordination. However, there are still various challenges that remain with respect to institutional fragmentation in transport and land use. These can be summarised as a lack of: i) interconnectivity, ii) coherence across transit modes, iii) regional freight planning, iv) accountability and v) implementation power. These challenges are described below.

Although we did not quantify the costs of this institutional fragmentation, one can assume that they are substantial. Improvements on the five challenges would arguably reduce the economic costs of congestion in Chicago, estimated to be at over USD 8 billion in 2010 by the Texas Transportation Institute. Congestion costs have important economic impacts on worker productivity and on the freight and logistics sector, one of the flourishing economic clusters in Chicago (Staley, 2012). Lacking interconnectivity also reduces positive agglomeration effects, as it hinders potential commuting within a larger metropolitan area, and thus reduces the positive labour market matching effects in a large metropolis. Improvement on the following five challenges will thus have positive economic impacts.

\subsection{Smooth interconnectivity}

The current state of transit ridership in Chicago is relatively depressing. Whereas the vast majority of transit users in the Chicago region live in the core, less than $30 \%$ of the City of Chicago residents take transit to work. The vast majority of Chicago region residents drive to work, which can be explained by a transit system that is too radial to serve non-downtown trips well, and by the lack of frequent all-day

5. CMAP also includes a seventh county, Kendall. 
service to areas outside the centre (MPC, 2013c). As a result, a smaller share of Chicago commuters uses transit than in 1980, with a transit system that carries $20 \%$ fewer passengers than in 1980 . The only ridership growth has taken place in Chicago's central neighbourhoods (MPC, 2013c).

Limited ridership is related to the lack of an integrated public transit system in Chicago. The provision of transit services follows an administrative jurisdictional logic instead of a logic motivated by traffic flows. The system is neither suited for city-to-suburb traffic nor for suburb-to-suburb traffic. Approximately $36 \%$ of Chicago's population works outside the city of Chicago, and $46 \%$ of workers in the city of Chicago live in the suburbs. Yet the division of the transit system into an urban (CTA) and suburban part (Pace and Metra) means that a large share of these commutes is not transfer-free. Although CTA rail services extend beyond the city limits, this is not the case for the CTA bus services, focused almost entirely on the city of Chicago. CTA bus services typically end abruptly at the city limits where Pace services begin. It is rare for CTA buses to continue out to suburban job locations or for Pace bus lines to extend into urban cores according to the MPC $(2013 \mathrm{c}){ }^{6}$ A similar system fragmentation exists with respect to rail services. None of Metra's downtown commuter rail connects directly to the CTA rail network, with only two stations that provide true intermodal connections between CTA and Metra systems, namely Oak Park and Jefferson Park (MPC, 2013c). ${ }^{7}$ Due to the radial structure of the public transit network (with the city of Chicago at the core), increased sub-urban to sub-urban traffic flows cannot really be accommodated by public transport. Attempts to link the RTA network to the regional transport networks in the other states (Indiana and Wisconsin) have not materialised, due to limited political commitment and priority.

There are various instances of insufficient coordination between the different services boards. For example, Metra began its 2010 Union Pacific-North Line bridge reconstruction project without coordination with the alternative parallel CTA bus and rail service, which resulted in severe service disruptions; consequently the project had to be stopped and re-planned. In 2013, the CTA initiated the Dan Ryan Reconstruction Project without taking into consideration the 10 000-14 000 Pace customers who take the bus into the $95^{\text {th }}$ Dan Ryan terminal each day, nor the availability of parallel Metra service. Due to lack of both coordination and advanced involvement of the other Service Boards, Pace had to scramble for funds to accommodate disrupted riders and Metra was asked to accommodate CTA customers with only four months' notice. In addition, there are evident advantages of joint procurement, which have only recently begun to be explored. ${ }^{8}$

This lack of integration constrains ridership. As commuter rail is not well connected to local bus services, only a low share of passengers arrives to the stations by bus (7\% in the early 2000s, the situation not having changed much since). Access to stations is dependent on the automobile, which requires a large amount of parking space. Downtown terminals have a large number of activities within walking distance, but reverse commuters cannot reach their final destination by foot because the location of suburban employment follows highways. It is estimated that $70 \%$ of the regional jobs are not within walking distance of rapid transit. This has a wider set of causes related to a lack of transit-oriented planning: just $22 \%$ of the regional population is located within half a mile of rapid transit stations, and just $8.5 \%$ is within a quarter mile of stations (MPC, 2013c). ${ }^{9}$ The institutional fragmentation in Chicago can be considered to be one of the causes of the absence of a high-speed rail connection between O'Hare airport and the city

6. An exception to this statement is the new bus on shoulder service Pace operates from the southwest suburbs onto the I-55 going down to the Chicago Central Area.

7. In addition, the Evanston Metra and CTA-Davis stations are adjacent to each other but not directly connected.

8. The examples mentioned in this paragraph were provided to us by Stephen Schlickman, Executive Director of the Urban Transportation Center at the University of Illinois at Chicago.

9. Rapid transit is here considered as the CTA L line, the Metra rail line and the future Ashland Avenue BRT. 
centre of Chicago, in addition to obvious engineering and cost challenges. O'Hare airport is located on land owned by the city of Chicago, but surrounded by sub-urban municipalities. The transaction costs to plan for a possible high speed corridor between the airport and the city centre - and the land acquisition that would be needed for this - have proved prohibitive.

Smooth interconnection is not helped by the absence of a harmonised fare structure in metropolitan Chicago. Each service board has its own fare structure, with the result that customers are treated differently according to which services they use. In general, long trips between destinations in the city of Chicago are cheap, whereas travel with similar distances but outside the city is much more expensive. In other words, there is hardly any relationship between transport fares and services that are used. These parallel fare structures also give disincentives to transfer between the different services (MPC, 2013c).

In addition, there is no single fare card for public transport in Chicago, even if some progress has been made. The Ventra card system, implemented by CTA and Pace, is currently not compatible with Metra that has its own fare card, apparently for sunk investments in its own fare collection system. Monthly Metra pass holders may also purchase a Pace bus sticker in conjunction with their monthly pass purchase, which provides access to Pace suburban busses. A CTA link-up option is also available for purchase. State law requires that all three agencies accept a single fare card by 2015, but there are currently limited indications that this timeline is going to be achieved. The Ventra card is designed to allow users with credit cards to use those as fare media instead of a traditional fare card.

\subsection{Coherence across transit modes}

The lack of alignment of strategies and instruments of different governments limits the coherence of travel mode policies for the region. The GO TO 2040 plan adopted the goal of doubling transit ridership by 2040 as a means of increasing mobility and creating more liveable communities. RTA policies support the modal shift proposed in GO TO 2040, but at the same time there are policies at various levels of government that stimulate car use; such as generous parking policies, a low gas tax that is relatively low from an international perspective, the lack of congestion charges or parking fees in most areas. As there is strong price elasticity between gasoline prices and transit use in Chicago (Nowak and Savage, 2013), one would expect that the modal shift targets are not facilitated by a policy that keeps the cost of car use low by under-pricing negative externalities of car travel.

Related to this is the lack of fluidity of funding across travel modes. Current funding distributions are often not based on thorough evaluation of project costs and benefits. Funding within the RTA is based on out-dated allocation formulas from the $1980 \mathrm{~s} .{ }^{10}$ According to these formulas, CTA receives $58 \%$ of the federal funds for transit in Chicago, Metra 34\% and Pace 8\%; a similar formula is applied to state funds with $50 \%$ allocated to CTA, $45 \%$ to Metra and 5\% to Pace. Only a very marginal share of the RTA budget (less than 1\%) is discretionary spending on which the main budgetary debates in the board are focused. As allocation formulas are decades old, they no longer correspond to current spending priorities and functional realities. However, these formulas turn out to be politically difficult to change, with the perceived losers from possible reform able to block changes due to the requirement of a supermajority action by the RTA Board. The lack of fluidity of transport funding also applies in a broader sense. Funds for roads are hardly used for public transit, and proceeds from toll ways have hardly ever been used for non-road transport. ${ }^{11}$

10. The formulas are not statutory but rather understood to be unchangeable political agreements.

11. Federal highway funds can be "flexed" (transferred) to transit through the MPO and or by consent of IDOT but this rarely happens except in the case of the Federal Congestion Mitigation and Air Quality program for which transit projects can compete and score well against highway projects. 


\subsection{Regional freight planning}

There is little regional coordination of freight traffic and logistics activities in the Chicago region. Location patterns are driven by the interplay of market developments and preferences of local governments. Most logistics activities have suburbanised, which is a logical development for a global city such as Chicago with high land rents in core urban areas and central business districts. The institutional fragmentation of the Chicago metropolitan area and the relative lack of a regional freight strategy imply that the location of logistics activity is becoming the outcome of local "NIMBY"-approaches. For example, temporary container storage spills over to jurisdictions that lack restrictive regulations or to municipalities far away from the urban centres that have sufficient undeveloped land. Many municipalities use aesthetic requirements in their zoning regulations or other restrictions to keep container storage areas out. For example, certain municipalities require container storage areas to be connected to waterways and railways, even if municipalities do not expect these containers to arrive by water or railways (Cidell, 2012). It is questionable if such a system of zoning regulations leads to the most rational organisation of freight traffic flows.

Institutional fragmentation also adds to the administrative burdens for truck drivers, with many of the local administrations in the region asking for separate licences to trucking companies. CMAP admittedly recognises the importance of coordination of freight policies. It calls upon the federal government to develop a vision, plan and funding to address freight nationwide, in parallel to efforts to improve the efficiency of the regional freight system. In that respect, it recommends the creation of a regional freight authority. This authority is envisioned to have the ability to finance freight system capital improvements and to address public policy issues, including community impacts such as delays, safety and noise. In addition, CMAP calls for full funding and implementation of the Chicago Region Environmental and Transportation Efficiency (CREATE) programme, a public-private partnership to achieve strategic rail improvements by reducing freight bottlenecks and raising operating speeds. Some actors currently consider the possibility of a CREATE 2-programme, that would be focused on reducing freight bottlenecks related to road transport.

Remarkably absent from these discussions about regional freight policies are the airports and ports of the region. Main airports in the region are the O'Hare airport and the Chicago Midway airport, both administered by the City of Chicago Department of Aviation (CDA). CDA has a strategic partnership with Gary Airport in Indiana, which allows it to install some sort of specialisation between the three airports, in conjunction with the modernisation of both O'Hare and Midway. ${ }^{12}$ The Illinois International Port District (IIPD) is the Port of Chicago, administered by a board appointed by the mayor of Chicago and the governor of Illinois. In the GO TO 2040 plan there is scant notice to the port and airports that from their side also seem to plan and operate without taking the GO TO 2040 plan into account. What could be considered the strategic plan of the IIPD, the 2012 Strategic and Capital Needs Study, does not mention the GO TO 2040 plan, nor does it position the port in the context of regional freight flows (BMO Capital 2012). It considers rail transport and the other ports in the region, such as the Port of Indiana-Burns Harbor, as competitors rather than as actors that provide complementary services.

\subsection{Accountability}

Public transit in Chicago is organised such that it is difficult to identify the main actor to hold accountable for underperformance. The RTA as a whole is constructed around the notion of a power balance between city and suburbs, with supermajority requirements that give the possibility to various actors to block decision making processes. Since 1983, a group of five RTA board members voting in

12. This inter-state cooperation also made it practically impossible to create a state-run airport authority, as was discussed at the time. 
unison can effectively veto decisions of the RTA Board of Directors. Since 2008, there is an equal balance of five members appointed by the Mayor of Chicago, five members from suburban Cook County and another five members of the so-called "Collar Counties" (the five counties surrounding Cook County), giving each of these sub-groups a veto. The structure of the CTA, with the city of Chicago appointing four of the seven board members, somehow makes the mayor of Chicago more accountable for issues related to the CTA. In Metra and Pace, power is more diffused among the suburban leaders, which makes accountability challenging. The current governance structure of public transport allows agencies to point fingers at each other when there are problems, e.g. with respect to the absence of a universal fare card, the unfinished Block 37-Station and the ADA Paratransit cost escalation (Schlickman, 2013). Under this structure the capital programming process is not comprehensible to users of the system. In addition, the sheer number of board members (47) creates a heavy management structure, not least as all of these are political appointees, not elected by the general public like in some other US metropolitan areas. Not surprisingly, public transit agencies, such as Metra, have been haunted by stories of cronyism and corruption, with the fragmented structure making it only more difficult for RTA to prevent this.

The road network in the Chicago region follows a completely incomprehensible pattern of mixed responsibilities. It is possible that the same road has parts that fall under the responsibility of the county, other parts under municipal jurisdiction, and yet other parts under the State. This can be explained by the fact that, in the past, responsibility over a road provided possibilities for a government to extract revenues, so that many governments competed to claim responsibility over roads or parts of roads. The result is a very fragmented structure of roads. The dispersal of responsibility for a road across several governments leads to huge transaction costs already for maintenance and repairs of one road, let alone for the transformation of a whole corridor. The situation also leads to underinvestment, e.g. when local governments are responsible for resolving an obstacle (e.g. a viaduct that is too low for trucks to pass under) from which they do not reap most of the benefits (as the economic benefits of increased truck traffic could spill over to other jurisdictions).

The fragmented road system adds to the lack of public accountability for transport in the region. The general public is not (and cannot possibly be) aware of which government is responsible for which part of which road; unlike other metropolitan areas in which it is generally possible to identify which types of roads are the responsibility of which type of government, the situation is much more complicated in Chicago. As such, the system of public accountability is diffused: even if it would be possible to identify the responsible actors for lagging performance, the fragmentation of responsibilities makes it all too easy for these actors to put the blame on other actors in the system. Rationalisation would be needed to clarify responsibilities for the road network in Chicago. For the moment, this is very difficult to realise, as no level of government would be tempted to accept this responsibility, considering the repairs needed to the roads and the drain this would represent for their public budget.

\subsection{Implementation power}

Chicago has a history of urban and regional planning that continues to foster bold, data-driven strategic visions, such as GO TO 2040. These planning exercises involve local scientists and a wide array of government actors, businesses, civil society actors and the general public at large; e.g. RTA's Regional Transit Strategic Plan also used contributions from the general public, which were released in the appendix to its plan. CMAP engaged with residents in online face-to face and in-situ deliberations on the long-term future of the Chicago region, using a digital tool for regional planning, MetroQuest, resulting in over 20000 Chicago-area residents becoming engaged (Haas Lyons et al. 2013). The strategic plans of the other regional planning organisations in the Tri-State Chicago Region, the NIRPC and SWERPC, are similarly thoughtful, data-driven and forward-looking. Even if one could comment on a lack of ambition in the long-term strategic plan of the RTA, regional strategic planning generally is not the main hiatus in Chicago; what is lacking are effective regional governance mechanisms to implement these visions and 
plans. The sections below focus on implementation of regional planning objectives and regional transit objectives.

\section{Implementation of regional planning objectives}

The CMAP does not have many instruments to enforce their regional plan. CMAP's primary permanent financing sources are federal funds dedicated to the agency as a metropolitan planning organisation (MPO), resources that are constrained to transport. The CMAP has no authority over other regional priorities connected to transport, such as natural resources, housing or economic development (MPC, 2013b). The CMAP does neither have its own revenues, nor the possibility to issue bonds, a common revenue source for sub-national governments in the US. It also does not have financial incentives or sanctions. The prerogative for land use is with local governments, so most of its power comes from working together with local governments. It has a technical assistance programme, which it has used for assistance to approximately 100 communities seeking to implement GO TO 2040, but this is a temporary initiative financed by a temporary grant from the US Department of Housing and Urban Development (HUD). Despite these handicaps, the CMAP has been described as a "skilled facilitator and convener" that managed to achieve some piecemeal progress towards implementation of its GO TO 2040 comprehensive plan (MPC, 2013b)

Unlike some other metropolitan planning organisations in the US, public transit planning is not integrated in CMAP. In Minneapolis, the primary transit operator is a part of the metropolitan planning organisation. In Vancouver (British Columbia), the region's equivalent of a metropolitan planning organisation is not only in charge of the operation of transit, but also for the region's main roadways. According to some observers, the separation of regional planning from regional transport planning (and operation) hinders the effectiveness of regional planning. For example, the Chicago Metropolis 2020organisation proposed in 1998 a Regional Growth and Transportation Commission to consolidate NIPC and CATS (which was implemented by creating CMAP), but also the planning components of the RTA and the Illinois State Toll Highway Authority into one agency. The larger consolidation did not happen, mainly out of concerns of concentrating too much power into one "super-agency" (Schwieterman and Mammoser, 2009). Some actors have mentioned the possibility of folding the RTA (and thereby oversight of the transport operating companies) into CMAP. However, CMAP is considered to have effectively formulated an ambitious and forward-looking regional plan with its GO TO 2040, and its public image and perception of effectiveness might conceivably suffer if it were to become associated not only with regional transit planning, but also with oversight of the public transport operators.

Not only regional, but also local land use plans are sometimes difficult to implement. An illustration in case is the land use planning system in the City of Chicago. Although the city is in charge of land use planning, most of this is actually taking place in concentration with the 50 wards of the city, each headed by a city council member. These wards engage in discussions with developers that result in negotiated planning outcomes that are relatively loosely connected amongst each other, as the city council does not interfere in what is going on in the wards, nor does the mayor unless he has major objections. Although observers seem to agree that this system generally functions well, it relativizes the power of the mayor of Chicago in providing long term land use plans.

\section{Implementation of regional transport objectives}

Like in regional planning, implementation challenges exist with regards to regional transport. Although the RTA has the legal mandate to oversee and plan for regional transit, its room is fairly limited due to the autonomy granted to the three Service Boards (CTA, Metra and Pace). This can be illustrated by the limited possibilities of the RTA to influence the budgets of the Service Boards: it can only accept or reject these budgets. The power of rejecting the entire budget could be considered too heavy an instrument 
to have practical use: the RTA does not want to be responsible for a service shutdown, which a rejection of the budget might imply, so it has not actually rejected a budget of the Service Boards. The RTA also does not have much power over the management of operations, unlike other regional transport authorities in the US. Both in New York and Philadelphia a single Board oversees and appoints management of all operations. Moreover, RTA board votes require a supermajority; this giving each area of the region veto power of the RTA's decisions and hindering the emergence of a regional perspective. The regional transit strategic plan of the RTA lacks the clarity and ambition of GO TO 2040; its long term financial vision falls short of being a comprehensive plan for future capital investments and operations with clear priorities and proposals for funding. It can be assumed that the complex regional organisation of public transit in Chicago can explain this void.

The lack of a regional vision on transit makes it more difficult to raise money for the transit system through state or federal funding, whilst this is urgently needed. Chicago's transit system is generally considered to be underfunded: not only does Chicago spend less on transit capital expenses than it did twenty years ago, with very slow growth rates in operational spending, but Chicago per capita transit spending is also falling behind that of many other cities in the US and internationally, e.g. London spends five times more on transit per capita than Chicago, New York more than three times more (MPC, 2013a). As of December 2011, the RTA required USD 18.7 billion to address the "state of good repair" backlog and an additional USD 12.4 billion to meet the ten-year need for normal capital re-investment, according to the RTA Capital Asset Condition Assessment Update (Delcan, 2013).

\section{POSSIBLE AVENUES FOR REFORM}

Various structures and frameworks in the Chicago Metropolitan area are outdated and inefficient, but these are difficult to change because reform is perceived as a zero-sum game. Historic developments explain the proliferated rate of local governments, the irrational organisational structure of the RTA with its Service Boards, and the funding allocation formula. Underlying these structures is a continuous battle between city and suburb, enforced by political divides along these lines. As many of the institutions in the Chicago region reflect a constructed equilibrium between city and suburbs, any efforts to change institutions touches this sensitive nerve. This means that reforms would have to be solidly built on the acknowledgement of win-win possibilities, and make use of windows of opportunity for change, such as crises or budgetary expansion. Past reforms in the Chicago region have often been adopted in times of budgetary crises. The history of the RTA provides a nice illustration of this point. Its creation in 1974, its reorganisation in 1983 and the new legislation in 2008 all took place within the context of financial problems, funding backlogs, potential bankruptcies and service disruptions, according to local observers.

Recent ethics controversies at Metra have created some momentum for reform. In response to these controversies the governor of Illinois created the Northeastern Illinois Public Transit Task Force in the summer of 2013 that reported in March 2014. The mandate of this taskforce was to identify potential reforms for region's transport agencies in terms of ethics, governance, finance and service standards. An important contribution of the Task Force has their recommendations to increase the ethical standards of board members of the public transit agencies, thereby contributing to restore the public image of the agencies. This could help to garner the public support that would be needed to solve the funding challenges of regional transit in Chicago, either by tariff increases, new tax revenues or other funding sources. Another set of recommendations relates to the governance of the transit system, where the task force proposes to create a single integrated agency with one board (instead of four) and three operating units 
(Northeastern Illinois Public Transit Task Force, 2014). The transformation of the RTA into a single transit agency could certainly improve its public accountability and regional coherence, but would need delicate designing and manoeuvring to succeed, compensating the mayor of Chicago for "losing" its political influence over CTA, without alienating the suburban leaders in the process.

Another window of opportunity could open with a new capital investment programme. Various observers expect that a new capital investment programme initiated by the State of Illinois might be in the making for 2015. This could provide the necessary momentum for metropolitan governance reforms. Directing certain capital funding streams via CMAP would increase its implementation powers; freightrelated capital projects could be linked to progress on the discussion on a regional freight authority, which might also be a function that the CMAP could host. Capital funding for regional transit could be linked to transformation of RTA into a single agency, to the phasing out of the funding formula for CTA, Pace and Metra, and to the creation of a funding model that is increasingly based on the merits of projects. A new capital budget could also increase the financial fluidity between different transport sectors and crosssectoral projects, e.g. congestion charging models in which part of the proceeds are used to stimulate public transit. Finally, a new capital programme could provide opportunities to present a more rational pattern of responsibilities for the roads in Chicago.

Related to this is the attraction of private finance for transport services, but experiences in this respect have been mixed in Chicago. The public-private partnership (PPP) on parking meters in Chicago is considered to be a textbook case of a bad PPP, as can be illustrated by a report from the City of Chicago Inspector General observing that the city was paid almost USD 1 billion less for the 75 -year lease than the city would have received from 75 years of parking meter revenue (Office of the Inspector-General, 2009). The contract contained "non-compete" and "compensation" clauses that mean that the city must reimburse the lessee, Morgan Stanley, for any time the space is used for anything other than parking, preventing road maintenance without paying a penalty; and from building parking lots for the entire duration of the contract because they might compete with the outsourced parking meters. Another PPP, the 99-year lease of the Chicago Skyway ${ }^{13}$ has raised criticism because of the toll increases and the absence of a provision in the contract that would enable the city to prevent this. The most recent experiences in the Chicago region appear also not to be very successful. The Illinois International Port District has so far not managed to get a firm bid for its terminals, whereas the proposed PPP for the Illiana Expressway would put most of the project risk in the hands of the public sector. Finally, the Chicago Infrastructure Trust, created in April 2012, has so far managed to get approval for only one project, worth USD 25 million of private investments, an amount earlier announced to be USD 115 million, overall a performance well below expectations.

New transformative projects could facilitate a regional win-win approach. Such a project-based approach could focus the attention of actors towards solving bottlenecks with regional benefits, e.g. along the lines of the CREATE programme. Whereas this programme was focused on the metropolitan area of Chicago in the stricter sense, new projects could also focus on cross-state projects. The only large crosssectoral project recently proposed, the Illiana Expressway, provides many indications of what to avoid: a project without a sound project evaluation appraisal, a PPP without transfer of risk to the private party, and uncoordinated recommendations of the two regional planning organisations involved, with CMAP recommending against it and NIRPC in favour. If new projects would be able to avoid such pitfalls and generate enthusiasm in the region, they might be able to transform current zero sum game approaches into a more constructive regional win-win approach to the challenges of transport and land use in Chicago.

13. The Chicago Skyway, also known as Chicago Skyway Toll Bridge System, is a 7.8-mile-long (12.6 km) toll road in Chicago carrying I-90 from the Indiana Toll Road to the Dan Ryan Expressway on Chicago's South Side. 


\section{BIBLIOGRAPHY}

Ahrend, R. et al. (2014), "What Makes Cities More Productive? Evidence on the Role of Urban

Governance from Five OECD Countries", OECD Regional Development Working Papers, 2014/05,

OECD Publishing, Paris, http://dx.doi.org/10.1787/5jz432cf2d8p-en.

BMO Capital (2012), Illinois International Port District; A Strategic \& Capital Needs Study, BMO Capital Markets, Acacia Financial Group, Cabrera Capital Markets.

CDOT (2013), Chicago Forward; Action Agenda, 2013 Update, City of Chicago, Department of Transportation.

Chicago Metropolis 2020 (1998), The Metropolis Plan: Choices for the Chicago Region, Chicago Metropolis 2020, Chicago.

Cidell, J. (2012), "Flows and Pauses in the Urban Logistics Landscape: The Municipal Regulation of Shipping Container Mobilities", Mobilities, Vol.7 (2), pp. 233-245.

Cidell, J. (2013), From hinterland to distribution center; The Chicago region's shifting gateway function, in: Hall, P. and M. Hesse (eds.) (2013), Cities, Regions and Flows, Routledge, New York and London.

CMAP (2010), GO TO 2040 Comprehensive Regional Plan, Chicago Metropolitan Agency for Planning, Chicago.

CMAP (2011), Handbook of Planning Law Principles and Practices for Northeastern Illinois, prepared by Duncan Associates and Rutgers University for Planning Practice, Chicago Metropolitan Agency for Planning, Chicago.

CMAP (2013), GO TO 2040 Moving forward; 2013 Implementation Report, Chicago Metropolitan Agency for Planning, Chicago.

Delcan (2013), Determining the Equitable Allocation of Public Funding for a Regional Transit System; Final Report.

Haas Lyon, S. et al. (2013), Exploring regional futures: Lessons from Metropolitan Chicago's online MetroQuest, Technological Forecasting \& Social Change.

Hamilton, D. (2002), "Regimes and regional governance: the case of Chicago", Journal of Urban Affairs, Vol. 24 (4), pp. 403-423.

Jacobs, J. (1961), The Death and Life of Great American Cities, Vintage Publishing.

Lascano Kezic, M. and P. Durango-Cohen (2012), "The transportation systems of Buenos Aires, Chicago and Sao Paulo: City centers, infrastructure and policy analysis", Transportation Research Part A, Vol. 46, pp. 102-122.

Lindstrom, B. (2010), "The Metropolitan Mayors Caucus: Institution Building in a Political Fragmented Metropolitan Region”, Urban Affairs Review, Vol. 46 (1), pp. 37-67. 
Metropolitan Planning Council (2011), Bus Rapid Transit: Chicago's New Route to Opportunity, Metropolitan Planning Council, Chicago.

Metropolitan Planning Council (2013a), The Public Transportation Network in Northeastern Illinois: An Analysis of Existing Conditions, Metropolitan Planning Council, Chicago.

Metropolitan Planning Council (2013b), Do We Have the Capacity for Transformative Investment? An Assessment of Northeastern Illinois' Regional Development Structures and Tools, Metropolitan Planning Council, Chicago.

Metropolitan Planning Council (2013c), Databook: The Public Transportation Network in Northeastern Illinois, Metropolitan Planning Council, Chicago.

Metropolitan Planning Council (2013d), The Costs and Benefits of the Illiana Expressway, Presentation for Board Discussion August 27 2013, Metropolitan Planning Council, Chicago.

NIRPC (2011), Comprehensive Regional Plan: A Vision for Northwest Indiana, Northwestern Indiana Regional Planning Commission, Portage, Indiana.

Northeastern Illinois Public Transit Task Force Report (2014), Transit for the $21^{\text {st }}$ Century, Illinois Department of Transportation.

Nowak, W. and I. Savage (2013), "The cross elasticity between gasoline prices and transit use: Evidence from Chicago", Transport Policy, Vol. 29, pp. 38-45.

OECD (2012), Territorial Reviews: The Chicago Tri-State Metropolitan Area, United States, OECD Publishing, Paris, http://dx.doi.org/10.1787/9789264170315-en.

Office of the Auditor General (2007), Performance Audit Mass Transit Agencies of Northeastern Illinois: RTA, CTA, Metra, and Pace, Office of the Auditor General State of Illinois, Springfield, Illinois.

Office of the Auditor General (2009), Status of Recommendations from the 2007 Performance Audit of the Mass Transit Agencies of Northeastern Illinois, Office of the Auditor General State of Illinois, Springfield, Illinois.

Office of the Inspector-General (2009), An Analysis of the Lease of the City's Parking Meters, Office of the Inspector-General, City of Chicago, June 2, 2009.

RTA (2012), The RTA Fact book 2012: The public transportation system serving Northeastern Illinois, Regional Transportation Authority, Chicago.

RTA (2013a), Regional Transit Strategic Plan 2013-2018, Adopted August 2013, Regional Transportation Authority, Chicago.

RTA (2013b), Ten-Year Financial Plan 2013-2022, September 2013, Regional Transportation Authority, Department of Finance and Performance Management, Chicago.

Schlickman, S. (2013), Letter to the Co-Chairs of the Northeastern Illinois Public Transit Task Force, October 8, 2013. 
Schwieterman, J., L. Audenaard and M. Schulz (2012), Tending to Transit: The Benefits and Costs of Bringing Public Transport in the Chicago Region into Good Repair, Working Paper, DePaul University, Chicago.

Schwieterman, J. and A. Mammoser, (2009), Beyond Burnham: An Illustrated History of Planning for the Chicago Region, Lake Forest College Press.

SEWRPC (2006), A Regional Land Use Plan for Southeastern Wisconsin: 2035, Southeastern Wisconsin Regional Planning Commission, Waukesha.

Smith, C. (2006), The Plan of Chicago; Daniel Burnham and the Remaking of the American City, The University of Chicago University Press.

Staley, S. (2012), Practical Strategies for Reducing Congestion and Increasing Mobility for Chicago, Reason Policy Study 404, Reason Foundation, Los Angeles.

Wiewel, W. and K. Schaffer (2001), "Learning to Think as a Region: Connecting Suburban Sprawl and City Poverty", European Planning Studies, Vol. 9 (5), pp. 593-611.

WBC (2012), A Plan for Economic Growth and Jobs, World Business Chicago, March 2012, Chicago. 